\title{
Rita Wilson
}

\section{City and labyrinth: Theme and variation in Calvino and Duranti's cityscapes}

\author{
I saw a splintered labyrinth (it was London) ... \\ I saw all the mirrors on earth and none of them \\ reflected me. \\ (J.L. Borges - The Aleph)
}

\begin{abstract}
For a number of Italian writers the modem city has come to mean as much a style, a fractured syntex, a paratactic sign-system, as a physical constnct with cenain demonstrable boundaries. In the works of such authors as Italo Calvino and Francesca Duranti the crisis of reason is symbolized by indeterminate aleatory structures - such as the labyrinth or the chessboard - all of which can be considered variations on the theme of the modem city. Calvino and Duranti's invisible or labyrinthine cities serve as an infinitely malleable poetic dramatization of the mind. The cities are both projections of their respective narrators and images that shape the reader's experience. By analysing the spatial structures of the narratives and by examining the use of space as a locus of fantasy this article shows how these novels chan cityscapes of the mind.
\end{abstract}

\section{Introduction}

When studying the city we confront problems of language as well as of methodology. Our perceptions of the urban landscape are inseparable from the words we use to describe them and from the activities of reading, naming and metaphorizing that make all our formulations possible. As the conception of the city as a physical entity has gradually yielded to one based on intangible relationships, many traditional disciplines have had to make room for the city as a subtopic of increasing importance (cf. among others Kevin Lynch, 1960; Sharpe \& Wallock, 1987; Timms \& Kelley, 1985).

\subsection{Cities as a mental topography}

Cities are possibly the largest and most social of human constructs and are efficient symbols for creating a kind of mental topography. They are highly visual, they are large and concrete, so that we may move within them; they seem to comprehend the whole of human experience in encyclopaedic fashion, and they enter into a dialectic with humanity: people shape cities, and cities shape people. It is not surprising that one of the recent 
dominant metaphors of our culture is that of 'world-become-city'.

If the Greeks perceived the cosmos as an immensely cxpanded polis, and medieval man saw it as a feudal manor enlarged to infinity, we experience the universe as the city of man. It is a field of human exploration and endeavour from which the gods have fled. The world has become man's task and man's responsibility. Contemporary man has become the cosmopolitan. (Cox, 1966:1.)

Writing at the turn of the century Georg Simmel (1969), among others, theorized about the impact of the urban environment upon patterns of human association and consciousness. For Simmel the urban experience bred among city dwellers a character that was rational, impersonal, alienated, unemotional and autonomous. ${ }^{1}$ Following Simmel, Robert Park felt that the city was something more than "congeries of individual men and social conveniences" (Park \& Burgess, 1967:3). Rather it was a "state of mind, a body of customs and traditions, and of the organized attitudes and sentiments that inhere in these customs and are transmitted with tradition" (Park \& Burgess, 1967:4). Thus the city was not simply defined as a spatial-distributive pattern but also as possessing a 'moral order'. Parks argued that the physical and moral organizations are mutually interdependent and interact in such a way as to mould and modify one another.

In expanding his definition of the city to include the presence of "an urban state of mind", Park has much in common with artists inspired by the atmosphere of the modern metropolis. In painting, literature and, to a certain extent cinema, the idea of the modern city is often difficult to separate from the physical change, social turmoil, psychological trauma and intellectual ferment bound up with the idea of modernism in general. Malcolm Bradbury relates the concept of artistic modernism to the urban environment in which it took shape. The city not only moulds artistic expression but almost parallels it: "... the cultural chaos bred by the populous, ever-growing city, a contingent and polyglot tower of Babel, is enacted in similar chaos, contingency, and plurality in the texts of modern writing, the design and form of modernist painting" (Bradbury \& McFarlane, 1976:96, 98-99). The city is the locus of modernism and each aspect of city life seems to generate or demonstrate a characteristic of this artistic movement - multiplicity of meaning, loss of sequential or causal connection, breakdown of signification, and dissolution of community.

\subsection{Cities in narrative}

In its representations of the city, narrative literature finds itself in an increasingly paradoxical situation. Narrative fiction is for the reader a temporal medium which must create the illusion of events happening in space. It also, however, depends on a succession of spatial scenes to give the narrative the illusion of the passage of time. The image of the city in a literary work occupies a singular position. Since its conceptual as well as its empirical referent is a physical object in space, the word-city is an inherently spatial image. Yet its association with spatiality conflicts in modern literature with the dominating convention of time. Thus many cities in contemporary literature are etherealized or disembodied. In this way their spatial presence is reduced so that they appear as dependencies of time. These 'semi-transparent' cities are overtly fantasies rather than toponymical representations of real places.

1 Simmel also points out that while the metropolis might lead to the corruption of 'mental life', it might also serve as a site of human emancipation. (See his essay "The Metropolis and Mental Life" in Sennett, 1969). 
For a number of Italian writers the modern city has come to mean as much a style, a fractured syntax, a paratactic sign-system, as a physical construct with certain demonstrable boundaries. 2 In the works of Italo Calvino and, more recently, Francesca Duranti, the crisis of reason is symbolized by indeterminate aleatory structures - such as the labyrinth or the chessboard - which can be considered variations on the theme of the modern city. Calvino and Duranti's invisible or labyrinthine cities serve as an infinitely malleable poetic dramatization of the mind. The cities are both projections of their respective narrators and images that shape the reader's experience.

\section{Fantasy as mental topography: Italo Calvino's Invisible Cities}

Calvino (1987:53), in particular, is fascinated by the topos of the city:

... the way is still open for a study of the symbol city from the Industrial Revolution on, as a projection of the terrors and desires of contemporary man. Frye tells us that the city is the human equivalent of the mineral world, in its apocalyptic or paradisiacal aspects (City of God, Jerusalem, soaring architecture, seat of the king and the court) or in its demonic and infernal aspects (City of Dis, City of Cain, labyrinth, modern metropolis).

As its title implies, his Le città invisibili (1972) takes as its immediate referent the architectural image of cities, cities with names that are differentiated according to their architecture and the social practices which that architecture facilitates. It matters less that Calvino's cities are mental constructs and therefore 'invisible' than that they create a fascination with the discoveries they engender. ${ }^{3}$ Calvino's cities are no doubt a metaphor for literature; they are the inner landscapes of desire and fantasy, and at the same time they are concretized in material structures and endowed with meanings.

\subsection{Spatial structure of Calvino's cityscapes}

Calvino's structure is very rigid, as if to create an abstract, spatial organization for the great conceptual freedom of the fantasy. An examination of the spatial structure of the book reveals some interesting facts about Calvino's cityscapes. The book is divided into nine sections; each opens and closes with a portion of the frame story presenting the conversation between Kublai Khan and Marco Polo. 4 The bulk of each section is a set of descriptions of cities. Sections 1 and 9 have the frame plus 10 cities each; sections 2

2 This is true too of many of the avant-garde movements. Cubism, Futurism, abstract art of many kinds are all tied to to an urban sensibility. The great modernists like Picasso, Boccioni, Kandinsky, who were more preoccupied with aesthetic than social issues, celebrated the 'universal dynamism' of modern urban life. (cf. Timms \& Kelley, 1985.)

3 In particular Marco Polo's discovery of new languages contains coherent meanings about real things.

4 In his famous Travels (ca, 1300) Marco Polo described, often in sumptuous detail, many of the cities he had visited. In Le cittd invisibili Marco Polo has been making such reports to the emperor of the Tartars, Kublai Khan. Polo's reports however have shifted from the factual to the fantastic: his cities are verbal constructs invented to amuse the emperor. The capricious categories into which the cities are divided reflect not the places themselves but the imaginer 'seeing' them as he narrates them. 
through 8 have the frame plus 5 cities each, totalling 55 cities and 18 frame pieces. 5 As regards the order in which the cities are deployed, there is an elaborate counting game. In each of the eleven categories of cities ${ }^{6}$ there are five cities. The cities are arranged in a complex pattern which maintains the principles of fives both vertically for each category and horizontally for each section. ${ }^{7}$

In contrast to the mathematical strictness of the presentation, the prose poems of the cities themselves are widely scattered in all sorts of implied space. If Kublai Khan and Marco Polo in their ordering are following the rational, the orderly and the linear, the cities seem to be associational, organic and free-form. The Khan and Polo are men, emblems of a military-commercial empire, but the cities partake heavily of the feminine: all of them have women's names and are energized largely by female characters. In Jungian terms, the invisible cities could be considered anima figures projected by the archetypal subconsciousness of the two men. Thus the men find themselves reduced to the rectilinear pattern of the chessboard, but the cities soar in unlimited space.

\subsection{Oneiric space}

Joseph Frank (1963:3-62), takes the Kantian categories of space and time as polar opposites, and uses the term spatial rather indefinitely to mean something like abstract, atemporal and non-linear. 8 His comments help us follow Calvino's emphasis on counting the cities. It is possible that this serial patterning may be a temporal countermove to the heavy spatial arrangement of the cities. The Khan and Polo may have been taken out of ordinary historical time, but the novel, for all its spatiality, signals its own internal time by its formal arrangements. These cities are 'invisible' because they exist only as inventions of the imagination of the narrator. By this device Calvino underscores the fact that wordcities do not exist in space but in narrative time. A useful notion in this context is that implied by Bachelard's term oneinic space:

The space in which we shall spend our nocturnal hours has no perspective, no distance. It is the immediate synthesis of things and ourselves. If we dream of an object, we enter that object as into a shell. Our oneiric space always has this cocfficient. (Bachelard, 1971:172.)

This term is a key for a reading of Invisible Cities: the implied space of the cities is only metaphorically exterior; phenomenologically, it is totally interior, both in the projection of

5 These numbers do not seem to have inherent meanings; Calvino has indeed avoided most of the traditional numerologies. Carter (1987:110) notes that "( ()ive and eleven (...) are sturdy prime numbers; sections 1 and 9 have twice the number of cities of the others, as if to stand as a solid frame around the smaller sections" but admits to not being able to establish any further symbolic overtones.

6 Cities and memory, cities and desire, cities and signs, thin cities, trading cities, cities and eyes, cities and names, cities and the dead, cities and the sky, continuous cities and hidden cities.

7 For a detailed discussion of the cities' layout see Carter (1987:110-112) and his detailed bibliographical note on the other critics who have constructed differing charts when discussing the novel's spatial qualities (1987:164-165).

8 Frank's work and also that of Bachelard (1969 and 1971:171-175) are particularly useful in a discussion of contemporary notions of 'spatiality', in which time operates as the cultural convention dominating our conception of the spatial world. 
it by Calvino through the Khan and Polo and in the perception and recreation of it by the reader.

\subsection{Spatial imagery}

A closer look at the spatial imagery makes for some suggestive readings. Despina, ${ }^{9}$ the third city in the group "Cities and desire", illustrates two uses of space: space and desire and reversible or negative space. The camel driver sees the city as a ship about to leave port for romantic voyages (p. 17 ; p. 25 ). The sailor, in contrast, sees the city as a camel and imagines caravans and oases and "palaces of thick, white-washed walls, tiled courts where girls are dancing barefoot" (p. 18; pp. 25-6). Each viewer projects his fantasies on the skyline of the city, perceiving the outline of a ship or a camel, according to his desires. Like a mirror the city reflects the viewer's desire and is variable, even reversible, according to the perspective from which it is viewed.

Then comes the twist: "Each city receives its form from the desert it opposes; and so the camel-driver and the sailor see Despina, a border city between two deserts" (p. 18; p. 26). Beyond mere reversibility, an inherent negativity exists in this projecting of desire: the sailor and the camel driver give form, create the city because of the sterility of their existence so that the city, as created by them, exists between two deserts. Thus the camel driver and the sailor seem destined to enter a desert on the other side of Despina, a mirage of desire, an empty fantasy that will disappoint the desires projected upon it. Each viewer "knows it is a city but he thinks of it as" a vessel or a camel, suggesting the kinetic nature of desire in fantasy, even with an accompaniment of realistic knowledge. ${ }^{10}$

Despina will also serve to illustrate some general characteristics of the poetic descriptions of the cities; all the descriptions are short, highly evocative in image and other appeals to the senses, but at the same time abstract in thematic concerns. The descriptions present a glossy, attractive though difficult style - a style even containing forbidding meanings: they often seem like conundrums or mystical riddles. Thus the descriptions arouse our desires but the philosophical problems are raised to acute, insoluble paradoxes. The very brevity of the sketches reinforces this dissonance. We are seduced into the fantastic landscapes only to find ourselves lost and disoriented in a conceptual maze.

\subsection{Calvino's use of pattern in space}

All these characteristics raises the question of Calvino's use of pattern in space. ${ }^{11}$ In effect, with each of Calvino's cities we drift into an oneiric state that illustrates and elicits desire,

9 The name Despina reminds us of the Mirtatious soubrette in Mozart's Cosi fan tufte, with the added analogy of spina (thorn in It alian), i.e. an attractive but barbed city: 17-18; 25-26. (All page references are from the 1979 Picador edition, followed by the page references from the original Italian version.)

10 Other citics which are especially vivid in showing desire in relationship to space are Chloc (Trading cities, 2; pp. 42-43; pp. 57-58); Anastasia, "city of sensuous delights" (Cities and desire, 2; p. 14; p. 20); Fedora (Citics and desire, 4 ; p. 28; p. 39).

11 In Octavia, "the spider-web city", (Thin citics, 5; p. 61; p. 81. Its name is probably a pun on the eight legs of spiders.) Calvino makes an adroit use of spatial images, mixing moods. On the one 
but that usually limits it by some sort of countermovement. Three kinds of cities seem particularly rich in mysterious resonances to metaphysical patterns: cities related to the sky, ${ }^{12}$ double cities and cities that refashion themselves.

The reflection between heaven and earth portrayed in the "Cities and the sky" represents a kind of polarity that is found more explicitly still in the double cities. A traveller to Valdrada (Cities and eyes, 1; pp. 43-44; pp.59-60) sees two cities built on a lake, the earthly and the mirror image.

The twin citics are not equal, because nothing that exists or happens in Valdrada is symmetrical: every face and gesture is answered, from the mirror, by a face and gesture inverted point by point.

The inversion often changes value and generally seems to unsettle the inhabitants. This optical damnation locks them in a closed system where both freedom and privacy are denied, making Valdrada one of the most undesirable of the invisible cities. ${ }^{13}$

The most complex spatial permutations are naturally offered by the cities that constantly recreate themselves. ${ }^{14}$ Berenice (Hidden cities, 5; pp. 124-25; pp. 166-67) synthesizes

hand, the city is a delight of design: it is suspended between two mountains by a net; from this net everything hangs below. Calvino plays a lovely melaphysical game in his calalogue of hanging items: "rope ladders, hammocks, ... baskets on strings, dumbwaiters, ... trapczes and rings for children's games, cable cars, chandeliers, pots with trailing plants". The reader fecls the delight of invention, of unexpected connection, and the playfulness of this grandiose spatial game. But on the other hand: the inhabitants "know the net will only last so long". Calvino has deliberately chosen to make this counterpoint. He could have chosen to show that the inhabitants, like spiders, renew the net and so shall hang forever but, in three bricf paragraphs, he establishes a lavish set of images, and two conflicting moods: desirc, however concretized and celcbrated, has a terminus of death.

12 Eudoxia (Citics and the sky, 1; pp. 76-77; pp.103-4) is the city that resembles a carpel. An oracle has suggested that the city "has the form the gods gave the starry sky" but "you could, similarly, come to the opposite conclusion: that the true map of the universe is the city of Eudoxia". Thekla (Citics and the sky, 3 ; p. 101; p. 134) is also chaotic, apparently unplanned, certainly unfinished; it takes the stars for a blucprint.

13 In contrast to Valdrada, the two halves of the delightful Sophronia (Thin cities, 4 ; p. 52; p. 69) form a harmonious and symbiotic whole. There is the circus half and the business half, and one of these is dismantled periodically and taken away on tour. Calvino's joke is quickly apparent: it is the business half which goes on tour. Of interest to the reader is the effect of variations and surprises found in the permutations of spatial arrangements rather than thematic conclusions. At least six other cities can be described as 'double': Maurilia (Cities and memory, 5, p. 27; pp. 37. 8) exists in the present and, via post cards, in the past. Zemrude (Cities and eyes, 2; p. 54; p. 72) has an upper and lower side; Becrsheba (Cities and the sky, 2; pp. 89-90, pp. 117-18) has a corresponding heavenly city; and Marozia (Hidden cities, 3; pp. 119-120, pp. 160-61) is simultancously two cities - that of the rat and that of the swallow. Eusapia (Cities and the dead, 3; pp. 88-89; pp. 115-16) houses all its dead in an identical city constructed bencath the ground. Laudomia (Cities and the dead, 5; pp. 111-13; pp. 147-49) is a double city of life and death.

14 Clarice (Citics and names, 4; pp. 86-7; 112-12) kecps recreating itself on the same sitc, while Ersilia (Trading cities, 4 ; p. 61-2; p. 82) moves as soon as it becomes too crowded with the strings that the inhabitants stretch between houses to show relationships. Leonia (Continuous cities, 1; pp. 91-2, pp. 119-20) refashions itself in the sense that it recycles its materials; sending the old Lconia (garbage) out into the countryside. 
conceptual permutation: a just city is hidden within an unjust city. But the seed of still another unjust city is hidden in the just city, so that "the real Berenice is a temporal succession of different cities". Berenice is the last city depicted in the book, and the closing lines of its description offer something of the potential that all the cities have been exploring: "all the future Berenices are already present in this instant, wrapped one within the other, confined, crammed, inextricable" (p. 125).

There is no global map of Calvino's cities, only a sheaf of insets in an atlas whose order is either unknown or fanciful. The world in which they are located has a rhizome structure: that is, it can be structured but is never structured definitively. The eighteen sections of the frame merely introduce and reflect upon the descriptions of the cities and the Khan and Polo are like disembodied oracles, whose conversations are highly self-conscious discussions of what the book is about. The major themes of the frame can be identified as follows: patterns (especially of desire) within the vast range of material decadence and conceptual possibility, the evocation of language beyond itself, and the participative nature of interpretation, by which we ourselves become emblems, at a level more abstract and hypothetical than the level of fact.

Images of the atlas and the chessboard are used to summarize and conclude the frames. ${ }^{15}$ The chessboard can be considered an emblem of cities emphasizing pattern and space, the atlas is an emblem representing other patterns and worlds. The two final portions of the frame to section 9 discuss an atlas which lists all possible cities. This atlas is magic in its detail and in its prophetic ability, describing cities not yet found. The atlas ends at a point beyond form: the death of the city by urban sprawl, formless and cancerous. The atlas (pp. 106-9; pp. 126-27) also describes utopias and dystopias, cities of pure desire and fear, archetypal cities of Bachelard's oneiric space. We are left, with the feeling that the pattern is "so subtle it could escape the termites' gnawing" (p. 10) is perhaps too subtle or too multiform for us to find.

\section{The city as labyrinth}

The 'absent structure' in Calvino's novel is that of the city as labyrinth. Calvino's cities may provide a 'topography of desire' but their complex lay-out also seems to embody the abstract model of conjecturality postulated by Umberto Eco (1989:57-58):

15 The initial somewhat latent images of the chessboard expand to a controlling metaphor in the opening and closing frames of section 8 (pp. $96-7,104$; pp. 127-29, 139-40). The Khan hopes to discover an order to his empire:

If each city is like a game of chess, the day when I have learned the rules, I shall finally possess my empire, even if I shall never succed in knowing all the cities it contains (p. 96; p. 127).

Then the trope is reversed: instead of reducing the cities to a chessboard, the two men attempt to use the chessboard to imply or create cities. Marco needs travel no more, and they sit, playing chess, Kublai looking all the while for an ultimate pattern but finding that all the cmpire "was reduced to a squarc of planed wood; nothingness ..." (p. 104) This final paragraph is repeated at the opening of the next bit of frame, the one completing section 8, suggesting that all the citics of section 8 were projected from the chessboard. Kublai remains dazed by the concept of nothingness, but Polo takes the chessboard as a point of departure to talk about "cbony forests, about rafts laden with logs ... of docks, of women at the windows" (p. 104; p. 140) as if to give the plenitudinous opposite to the Khan's reductionist despair. 


\begin{abstract}
An abstract model of conjecturality is the labyrinth. But there are three kinds of labyrinth. One is the Greck, the labyrinth of These us. This kind does not allow anyone to get lost: you go in, arrive at the center, and then from the center you reach the exit. This is why in the center there is the Minotaur; if he were not there the story would have no zest, it would be a mere stroll. Terror is born, if it is born, from the fact that you do not know where you will arrive or what the Minotaur will do. But if you unravel the classical labyrinth, you find a thread in your hand, the thread of Ariadne. The classical labyrinth is the Ariadne's-thread of itself.

Then therc is the mannerist maze: if you unravel it, you find in your hands a kind of tree, a structure with roots, with many blind alleys. There is only one exit, but you can get it wrong. You need an Ariadne's-thread to keep from getting lost. This labyrinth is a model of the trial-and-error process. And finally there is a model of the net, or rather what Delcuze and Guattari call "rhizome". The rhizome is so constructed that every path can be connected with every other one. It has no center, no periphery, no exit, because it is potentially infinite. The space of conjecture is a rhizome space.
\end{abstract}

According to Eco, this would be a deliberate strategy by Calvino to draw attention to the labyrinthine structure of the novel itself. As the city can indeed be considered the locus of modernism so the labyrinth can be viewed as pre-eminently a sign of the modern, probably because its visual pattern mimics our preoccupation with the dynamic configuration of urban living space. As 'a symbol for the world' the labyrinth suggests the experience of urban disorientation within a formal pattern captured in a New Yorker cartoon depicting "a minotaur contemplating a subway map" (Faris, 1988:178). 16 In its three-dimensional form, the modern labyrinth extends the lexicon of sculptural design into the contemporary environment everywhere.

As Eco has pointed out, obsessive exploration of labyrinths may be associated with the original structure at Knossos. In fact, this prehistory frames our perception of labyrinthine landscapes. The classical design of the labyrinth probably formed part of the city's defences, whereas in our time instead of the castle or town protected by a labyrinth we see the city as labyrinth.

The city as spatial form presents both the image of a map and the image of a labyrinth. In Francesca Duranti's fiction the central labyrinth pattern is not sculptural design so much as textual reinvention, for "the labyrinths of the city are duplicated in the labyrinths of language" (Faris, 1988:181). Her protagonist is provided with the means to orientate herself spatially: a map of the city. However, no matter which way she reads the map, or which route she takes, she cannot find the house she is seeking. This map's only function is to project the stages of her journey in terms of a temporal narrative.

\title{
3.1 Escape from the labyrinth: Francesca Duranti's Personal Effects
}

It is the labyrinthine path itself that Duranti's novel, Effetti personali (1988), mimics in its transformation of the visual and spatial iconography of the three-dimensional city-labyrinth into the temporal and linear design of the text. She employs a line of writing which mimics the multicursal paths of the original design so that her narrator/explorer encounters "a

16 In this wide-ranging study Faris discusses a good many texts whose art is devoted to the reconfiguration of the labyrinthine form in the shapes of postmodern fiction. 
landscape that includes both alternatives and entrapments ... simultaneous confusion and compulsion" (Faris, 1988:4). Although this work may in some ways be considered a 'confessional novel' in that it reconstructs the personal history of the narrator/protagonist, the author also feels impelled to make a story out of a city

... to represent the strects and the various districts as dramatis personae, each one with a character in conflict with every other; to give life to human figures and situations as if they were spontaneous growths from the cobbles of the strects, or clse protagonists in such dramatic contrast with them as to cause a whole string of disasters; to work in such a way that at every changing moment the true protagonist was the living city (Calvino, 1987:182). 17

Duranti's enthusiasm is aroused by the topographical epic poem of the city, following her first intuition of the city as language, ideology, as the conditioning factor of every thought and word gesture, the streets that through their 'physiognomy' impart certain ideas, the city as mirror image or as mirage. Duranti's nameless East European city seems to combine the polarity of Calvino's double cities with the projection of desire in space.

The treatment of the exteriors is matched by those of the interiors, luxurious or squalid as they may be. The description of the Writer's Union and the intricacies of the municipal bureaucracy crowns the whole design. The act of writing is equated to the charting of unknown territories.

\subsection{The quest for identity, the search for meaning}

The protagonist's quest is to find the best selling author Milos Jarco and to interview him in order to establish just how he manages to maintain a perfect ideological equilibrium in his writing between East and West and how his books have achieved major critical acclaim while being a great commercial success. This quest is inextricably linked to the search for her own identity and for the "via di mezzo" (pp. 22-23, 126).

The protagonist's ex-husband appropriates what remains of her identity by removing the brass plate from the front door of their (now her) apartment. Thus her name no longer names her, is has no solidity. This moment of revelation comes to her early in the novel ( $p$. 9) and her recognition of herself as a subject inhabited by lack and without 'personal effects' acts as the narrative motor. She embarks on a journey which seeks to fill the absence, the planned interview with the elusive author representing her only hope of survival by allowing her to keep on writing.

The novel demands an interactive reading: through her confrontation with the bifurcations, impediments, circularities and false trails of the city (and of the text), the narrator/explorer (and with her the reader) must choose which path (and thus which reading) to pursue.

The punto di mezzo becomes a recurring motif in the novel. The broad, deserted Hapsburg avenue which divides the city in half (pp. 64,77), creating two antithetical cities, is its

17 This comment on Balzac's Ferragus by Calvino (1987:182) is also a particularly apt description of Duranti's novel. 
physical representation. Like Calvino's lake in the description of Valdrada the street has the disconcerting effect of altering the characters' spatial perspective (p. 94), depending on which side of the street they are standing, raising complex questions around truth and falsehood (pp. 104, 166). It seems as though the world exists only as artifice, misunderstanding, falsehood. Not only does the distinction between fiction and reality become blurred, the author for whom she is searching turns out to be the product of a great literary fraud. There is no Ultimate Author, only a textual architect (p. 150) who has perfected the recipe for writing stories (pp. 139, 151): the perfect "literature machine".

Back from her voyage the narrator (and the reader), saturated with emotions and with writing, begins to apprehend something much more significant: not merely the accumulation of obstacles the text has set up against the quest for $a$ meaning, but the fact that the text itself has become both quest and obstruction. The text has first written itself into being through the intervention of the reader, and then has 'erased' itself as part of the same process.

\subsection{A mythology of the metropolis}

The strength of the whole novel is maintained and condensed by its being based on a mythology of the metropolis. Duranti discovers the city as a den of mysteries, and the sense she keeps ever-alert is that of curiosity. Her narrator is always delving into a tangle of things with the air of someone who scents a mystery and promises one. Her judgments and observations are those of a suspicious investigator with her hands on a mystery that must at all costs be solved. Unlike Calvino's potentially infinite labyrinth, Duranti's city mimics the mannerist maze. Thus the narrator's method of investigation is one of trial-and-error and her resolution of the mystery coincides with her escape from the labyrinth.

Besides providing a model for language, the labyrinth constantly reveals its cultural roots in another 'postmodernist' manner. Genealogy insinuates memory and desire into the textual labyrinth: the image 'remembers' its original values. The labyrinthine pathway is strewn with the ruins of the past, it reconstitutes a textual archaeology of 'visual reminders' and linguistic echoes. Because of this subtext the literature of the labyrinth recomposes itself continually into "a broad kind of intertextuality, a partial rewriting of the original myth" (Faris, 1988:201). Moreover, the labyrinth may be read as a sign of language itself and of writing for, in the words of Wendy Faris, it "embodies the sense in which we control and yet are controlled by language, in which we write and are written" (1988:4).

This metalanguage of the labyrinthine sign suggests that the path of the labyrinth is necessarily recursive, returning to the controlling original image of Knossos. In the postmodernist text of the labyrinth both Theseus and Daedalus (i.e. both the explorer and creator) are celebrated. The reflexive labyrinth provides "a potent and ubiquitous sign that stands for modern and contemporary fabulation" (Faris, 1988:12). In Calvino and Duranti's metanarratives their cities become images of "the splintered labyrinth" (Borges) and their characters continue to grapple with the description of "the unimaginable universe". 


\section{Bibliography}

Bachelard, Gaston 1969. The Poetics of Space. Trans. Maria Jolas. Boston : Beacon Press.

Bachelard, Gaston 1971. The Right to Dream. Trans. J.A. Underwood. New York : Grossman.

Bradbury, M. \& McFarlane, J. 1976. Modemism. Harmondsworth : Penguin.

Calvino, Italo 1972. Le città invisibili. Torino : Einaudi.

Calvino, Italo 1979. Invisible Cities. Trans. William Weaver. London : Picadot.

Calvino, Italo 1987. The Literature Machine. Trans. P. Creagh. London : Secker \& Warburg.

Cartcr, A.H. 1987. Italo Calvino. Metamorphoses of Fantasy. Ann Arbor, Michigan : U.M.I. Research Press.

Cox, Harvey 1966. The Secular City. New York: The Macmillan Co.

Duranti, Francesca 1988. Effetti personali. Milano : Rizzoli.

Eco, Umberto 1989. Reflections on the Name of the Rose. Trans. William Weaver. London : Secker \& Warburg.

Faris, W.B. 1988. Labyrinths of Language: Symbolic Landscape and Narrative Design in Modem Fiction. Baltimore : John Hopkins University Press.

Frank, Joseph 1963. The Widening Gyre. New Brunswick : Rutgers University Press.

Lynch, Kevin The Image of the City. Cambridge, Mass. : M.I.T. Press.

Park, R.E. \& Burgess, E.W. 1967 (1925). The City. Chicago : Houghton Mifflen.

Scnnell, R. (ed.) 1969. Classic Essays on the Culture of Cities. New Jersey : Englewood Cliffs.

Sharpe, W. \& Wallock, L. (eds). 1987. Visions of the Modem City. Baltimore : The Johns Hopkins University Press.

Timms, E. \& Kelley, D. 1985. The Unreal Ciry. Urban Experience in Modem European Literature and Art. New York : St. Martin's Press.

\section{University of the Witwatersrand}


